DR. NIDHI GARG (Orcid ID : 0000-0003-1563-6792)

PROF. STEVE VUCIC (Orcid ID : 0000-0002-0956-4633)

DR. YU-ICHI NOTO (Orcid ID : 0000-0003-1169-8574)

Article type : Original Article

\title{
Conduction block in immune-mediated neuropathy: paranodopathy versus axonopathy
}

Nidhi Garg ${ }^{1,2}$, MBBS; Susanna B. Park ${ }^{1}$, PhD; James Howells ${ }^{1}$, PhD; Steve Vucic ${ }^{3}$, PhD; Con Yiannikas ${ }^{4}$, MBBS; Emily K. Mathey ${ }^{1}$, PhD; Toan Nguyen ${ }^{1}$, Dip; Yu-ichi Noto ${ }^{1}$, PhD; Michael H. Barnett ${ }^{1,2}$, PhD; Arun V. Krishnan ${ }^{5}$, PhD; Judith Spies ${ }^{1,2}$, PhD; Hugh Bostock ${ }^{6}$, PhD; John D. Pollard ${ }^{1,2}$, PhD; Matthew C. Kiernan ${ }^{1,2}$, PhD DSc.

\section{Affiliations:}

1. Brain and Mind Centre, Sydney Medical School, The University of Sydney, NSW, Australia

2. Department of Neurology, Royal Prince Alfred Hospital, Sydney, NSW, Australia

3. Departments of Neurology and Neurophysiology, Westmead Hospital, University of Sydney, NSW, Australia

4. Department of Neurology, Concord and Royal North Shore Hospitals, University of Sydney, NSW, Australia

5. Prince of Wales Clinical School, The University of New South Wales, NSW, Australia

6. MRC Centre for Neuromuscular Diseases, National Hospital for Neurology and Neurosurgery, Queen Square, London, United Kingdom and Institute of Neurology, University College London, United Kingdom

Running title: Conduction block in immune-neuropathy

This article has been accepted for publication and undergone full peer review but has not been through the copyediting, typesetting, pagination and proofreading process, which may lead to differences between this version and the Version of Record. Please cite this article as doi: 10.1111/ene.13953

This article is protected by copyright. All rights reserved. 
Corresponding Author/Institution of study:

Professor Matthew Kiernan

Brain and Mind Centre, University of Sydney

94 Mallett Street Camperdown

NSW 2050, Australia

E:matthew.kiernan@sydney.edu.au

$P:+61291144250$

F:+61291144254

Keywords: neurophysiology, neuromuscular, autoimmune, multifocal motor neuropathy, chronic inflammatory demyelinating polyneuropathy

Conflict of interest:

HB receives from UCL a share of the royalties for sales of his Qtrac software. All other authors have no conflicts of interest to declare.

\section{ABSTRACT}

Background: Conduction block is a pathognomonic feature of immune-mediated neuropathies. The aim of this study was to advance understanding of pathophysiology and conduction block in chronic inflammatory demyelinating polyneuropathy (CIDP) and multifocal motor neuropathy (MMN). Methods: A multimodal approach was used, incorporating clinical phenotyping, neurophysiology, immunohistochemistry and structural assessments. Results: Of 49 CIDP and 14 MMN patients, 25\% and 79\% had median nerve forearm block, respectively. Clinical scores were similar in CIDP patients with and without block. CIDP patients with median nerve block demonstrated markedly elevated thresholds and greater threshold changes in threshold electrotonus (TE), while those without did not differ from healthy controls in TE parameters. In contrast, MMN patients exhibited marked This article is protected by copyright. All rights reserved. 
increases in superexcitability. Nerve size was similar in both CIDP groups at the site of axonal excitability. However, CIDP patients with block demonstrated more frequent paranodal serum binding to teased rat nerve fibres. In keeping with these findings, mathematical modelling of nerve excitability recordings in CIDP patients with block support the role of paranodal dysfunction and enhanced leakage of current between the node and internode. In contrast, changes in MMN likely resulted from a reduction in ion channel density along axons. Conclusions: The underlying pathology in CIDP and MMN are distinct. Conduction block in CIDP is associated with paranodal dysfunction which may be antibodymediated in a subset of patients. In contrast, MMN is characterised by channel dysfunction downstream from the site of block.

\section{INTRODUCTION}

Disease mechanisms and antigenic targets remain largely elusive in chronic inflammatory demyelinating polyneuropathy (CIDP) and multifocal motor neuropathy (MMN). Correlating clinical phenotypes with pathophysiology will be required before targeted treatment approaches can be developed. Conduction block (CB), occurring when an action potential fails to propagate through an axonal segment, is a pathognomonic feature of $\mathrm{MMN}$ and is frequently observed in $\mathrm{CIDP}^{1}$. Understanding the mechanistic basis of $\mathrm{CB}$ will provide critical information to guide the development of diagnostic and treatment approaches.

Nodal and paranodal regions have been implicated as key antigenic targets in CIDP ${ }^{2,3}$. IgG4 antibodies directed towards protein complexes at the paranode, including neurofascin- 155 (NF155), contactin-1 (CNTN1) and contactin-associated protein 1 (Caspr) $)^{4-7}$ have been

This article is protected by copyright. All rights reserved. 
described with patients tending to have a more severe phenotype, frequently refractory to standard first-line therapy ${ }^{6,8}$. Furthermore, IgM antibodies directed against GM1, a ganglioside enriched in the nodal and paranodal regions ${ }^{9}$, are found in some patients with MMN, but their role in pathogenesis remains unclear ${ }^{10}$.

To better understand the mechanism of $\mathrm{CB}$ and associated paranodal function, the present study incorporated comprehensive clinical assessments, neurophysiology, immunopathology and structural assessments to improve understanding of pathophysiological mechanisms underlying CIDP and MMN.

\section{MATERIALS AND METHODS}

\section{Patient selection}

Consecutive patients fulfilling criteria for definite or probable CIDP and MMN were prospectively recruited between April 2015 and January $2017^{11,12}$. Patients testing positive for NF155, CNTN1 or NF186 IgG4 were excluded. All participants gave written informed consent to participate in the study. The study was approved by the Sydney Local Health District Ethics Review Committee (Royal Prince Alfred Hospital).

This article is protected by copyright. All rights reserved. 


\section{Assessment tools}

Clinical assessments

Clinical assessments included assessment of muscle strength, grip strength and disability scores $^{13,14,15,16}$ (eMethods1, online).

\section{Neurophysiological investigation}

Comprehensive nerve conduction studies (NCS) were performed using Synergy software (Version 20.0). Patients with $\mathrm{CB}$ within the forearm segment of the median nerve were classified as CIDP (CB) or MMN (CB). As very distal and proximal CB can be difficult to accurately identify, this was not included in the CB group. The remaining CIDP patients without median nerve forearm block were classified as CIDP (eMethods2, online).

To assess axonal properties near the site of block, nerve excitability studies were undertaken on the median nerve at the wrist using the TRONDNF protocol within QTRACW software (C Institute of Neurology, University College London, UK) ${ }^{17}$ in patients with a distal abductor pollicis brevis CMAP > $1 \mathrm{mV}$. Patients with extremely elevated thresholds who did not tolerate the study were excluded from excitability analysis. Detailed methods and definitions of major excitability parameters have been previously described ${ }^{17-20}$ (eMethods3 online). Results were compared with 29 age-matched healthy controls (HC).

This article is protected by copyright. All rights reserved. 


\section{Mathematical modelling}

A mathematical model of the human motor axon was used to assist in interpretation of CIDP $(\mathrm{CB})$ and $\mathrm{MMN}(\mathrm{CB})$ recordings ${ }^{21-23}$. This 'Bostock' model consists of nodal and internodal compartments connected by the Barrett-Barrett conductance (GBB) which corresponds to current leakage pathways through and under the myelin sheath. Voltage-dependent ion channels, ion pumps, capacitance and leak conductances are incorporated into the model ${ }^{22}$. After matching the model to healthy control data, parameters were adjusted sequentially to determine which single parameter change resulted in the greatest reduction in discrepancy between the patient data and model. The best fit by two parameter changes was also determined through sequential changes in model parameters.

\section{Structural imaging}

The cross-sectional area (CSA) of the median nerve was measured at the wrist crease and forearm $^{24}$ (eMethods4, online). Results were compared with 29 age and sex-matched HC.

\section{Teased nerve fibre studies}

Animal experiments were approved by the University of Sydney Animal Ethics Committee (2016/943). Indirect immunofluorescence studies on teased nerve fibres were performed on serum from all CIDP patients as previously described ${ }^{7}$ (eMethods5 online). Where possible serum samples were collected before an IVIg dose (88\% of CIDP patients).

This article is protected by copyright. All rights reserved. 


\section{Statistics}

Statistical analysis and graph construction were performed using Graph Pad Prism 7 and IBM SPSS Statistics (Version 22) (eMethods6 online). Significance was defined by a p-value of $<0.05$ and adjusted for multiple comparisons where appropriate (defined as $\mathrm{p}<0.006$ for excitability data). Clinical results are presented as mean \pm standard deviation (SD) and excitability results as mean \pm standard error of the mean (SEM).

\section{RESULTS}

The patient cohorts demonstrated clinical phenotypes that were typical of CIDP and MMN (Table 1). There was no difference in age $(\mathrm{p}=0.83)$ or disease duration $(\mathrm{p}=0.09)$ across groups. There were no differences in clinical scores between patients in the CIDP (CB) and CIDP groups (MRC SS:p=0.49; grip strength:p=0.49; INCAT:p=0.80). Six out of $11(55 \%)$ of MMN patients tested positive for anti-GM1 IgM.

\section{Neurophysiological profiles}

Median nerve forearm CB was identified in 11 CIDP and $11 \mathrm{MMN}$ patients and 33 CIDP patients were without median nerve forearm CB (Table 1). There was no difference across groups in mean distal median CMAP amplitudes ( $\mathrm{p}=0.18)$. As expected, CIDP patients had longer distal motor latencies (DML) compared with MMN (CB) patients (CIDP: $4.6 \pm 1.8 \mathrm{~ms}$ $\mathrm{MMN}: 3.3 \pm 1.0 \mathrm{~ms} ; \mathrm{p}<0.05) . \mathrm{CIDP}(\mathrm{CB})$ patients had a more severe reduction in forearm conduction velocity compared with MMN $(\mathrm{CB})(\mathrm{p}<0.05)$ and CIDP $(\mathrm{p}<0.05)$ patients. Although patients in the CIDP group did not have median nerve forearm conduction block,

This article is protected by copyright. All rights reserved. 
94\% had abnormal NCS of the median nerve with $82 \%$ fulfilling EFNS/PNS criteria for demyelination in the studied nerve ${ }^{11}$.

Threshold properties

CIDP (CB) patients exhibited a marked increase in threshold compared with healthy subjects $(\mathrm{p}<0.0001)$ (Table 2, Figure 1,2A) requiring greater than three times the current to achieve $50 \%$ of the peak response. The CIDP group without median nerve forearm block demonstrated a smaller increase in threshold compared with $\mathrm{HC}(\mathrm{p}=0.009)$. In contrast, threshold was not significantly increased in the MMN (CB) group compared with HC $(\mathrm{p}=0.19)$.

Internodal properties

MMN (CB) patients demonstrated a "fanned out" threshold electrotonus compared to HC with changes in both depolarising and hyperpolarizing directions (Figures 1A, 2B, 2C). CIDP (CB) patients exhibited a similar pattern of changes in TE (Figures 1C, 2B, 2C), with greater threshold change to subthreshold hyperpolarising current evident (Figure 1E). In contrast, in CIDP patients without median nerve block in the intermediate segment, there were no significant TE changes compared HC (Figure 1G, 2B, 2C).

Recovery Cycle

Superexcitability was significantly increased in MMN (CB) patients when compared to CIDP (CB) patients (Fig 1F), CIDP patients without median nerve block and HC (Fig 1B, 2D). In This article is protected by copyright. All rights reserved. 
contrast, patients in both CIDP groups demonstrated no difference in superexcitability when compared with HC (Figures 1D, 1H, 2E).

\section{Mathematical modelling}

Chronic inflammatory demyelinating polyneuropathy

The single parameter change resulting in the greatest discrepancy reduction between CIDP (CB) patient and modelled data involved an increase in the Barrett-Barrett conductance (GBB) across the myelin sheath by $40.8 \%$, which reduced the discrepancy by $63.3 \%$. The best fit by two combined parameters was a $58 \%$ increase in GBB and $62 \%$ increase in fast $\mathrm{K}^{+}$ conductance resulting in a $78.1 \%$ discrepancy reduction.

Multifocal motor neuropathy

The single parameter change resulting in the greatest discrepancy reduction between MMN and modelled data was hyperpolarisation with $0.027 \mathrm{nA}$ current, which reduced the discrepancy by $73.1 \%$. A better fit was achieved by two parameters combining a $41.1 \%$ reduction in $\mathrm{K}^{+}$permeability and $56.1 \%$ reduction in persistent $\mathrm{Na}^{+}$, which reduced the discrepancy by $92 \%$.

\section{Structural nerve assessment}

There was no difference in nerve CSA between the two CIDP groups at either the wrist [CIDP:12.9 $\left.\pm 4.5 \mathrm{~mm}^{2} ; \mathrm{CIDP}(\mathrm{CB}): 11.1 \pm 1.6 \mathrm{~mm}^{2} ; \mathrm{p}=0.3\right)$ or forearm [CIDP:10.0 \pm 9.5

This article is protected by copyright. All rights reserved. 
$\mathrm{mm}^{2}$; CIDP $(\mathrm{CB}): 11.2 \pm 6.4 \mathrm{~mm}^{2} ; \mathrm{p}=0.2 ;$ eFigure1A-B online) suggesting that the marked increase in thresholds and TE changes in CIDP (CB) patients were unlikely to be primarily due to nerve enlargement. CIDP patients (with and without median nerve forearm $\mathrm{CB}$ ), exhibited greater nerve CSA compared with MMN patients at the wrist (all CIDP:12.5 \pm 4.0 $\mathrm{mm}^{2}$; MMN:9.4 $\pm 1.7 \mathrm{~mm}^{2} ; \mathrm{p}=0.007$ ), and forearm (all CIDP:10.3 $\pm 8.8 \mathrm{~mm}^{2}$; MMN:6.1 \pm $\left.1.1 \mathrm{~mm}^{2} ; \mathrm{p}=0.028\right)$ as well as $\mathrm{HC}$ at the wrist $\left(10.1 \pm 1.6 \mathrm{~mm}^{2} ; \mathrm{p}<0.005\right)$, and forearm $(6.2 \pm$ $0.8 \mathrm{~mm}^{2} ; \mathrm{p}<0.005 ;$ eFigure1C-D online).

\section{Teased fibre studies}

Nine out of 11 CIDP (CB) patients demonstrated binding at either the node, paranode and/or myelin compared with only 13 out of 33 CIDP patients $(81.8 \%$ vs.39.4\%; $\mathrm{p}<0.05)$ (Figure 3 ) While there was no difference in the proportion of patients demonstrating nodal binding between the two groups $(\mathrm{p}=0.09)$, patients with CIDP $(\mathrm{CB})$ more frequently demonstrated paranodal binding compared with CIDP patients (36.4\% vs.6.1\%; $\mathrm{p}<0.05)$ suggesting antibodies targeting paranodal structures may be linked to neurophysiological evidence of paranodal dysfunction. In contrast, only one patient with MMN demonstrated paranodal binding $(1 / 11 ; 9.1 \%)$, arguing against a primary paranodal mechanism in MMN.

\section{DISCUSSION}

The present study utilised a multimodal approach to examine pathophysiological mechanisms in immune-mediated neuropathy, linking neurophysiological evidence of paranodal dysfunction with an antibody response directed towards unidentified antigens in the paranodal region. There was no alteration in nerve size between the two CIDP groups on This article is protected by copyright. All rights reserved. 
ultrasound, while CIDP nerves were enlarged compared to MMN, indicating distinct structural nerve profiles. Furthermore, distinct axonal excitability profiles were identified in MMN compared with CIDP associated with conduction block, highlighting significant distinctions in underlying pathology.

Excitability results suggest that an increase in the conductance through and under the myelin sheath $(\mathrm{GBB})^{22}$, associated with an increase in fast potassium conductance may be a contributor to peripheral nerve dysfunction and conduction block in CIDP. Critically, both conductances are anatomically associated with the paranode or juxtaparanodal regions ${ }^{19}$. Loosening of the paranodal seal and greater leakage of current into the internode associated with paranodal demyelination would likely produce an increase in GBB and expose juxtaparanodal potassium channels, producing the pattern of changes demonstrated in CIDP patients with block, including higher stimulus thresholds for excitation and changes in TE. While an increase in GBB is typically associated with increased superexcitability (as seen in NF155 neuropathy $)^{3}$, this may have been counteracted by the reduction in superexcitability which occurs with an increase in fast potassium conductance ${ }^{25}$. Interestingly, patients with CIDP without block in the region of study did not demonstrate changes in TE and superexcitability parameters despite most demonstrating demyelinating features and nerve enlargement. Simulated models have demonstrated that axonal excitability properties may be normal when the degree of demyelination does not cause $\mathrm{CB}^{26}$.

A different pattern of excitability abnormalities was demonstrated in MMN with conduction block, consistent with previous findings ${ }^{27}$. Mathematical modelling suggested that these changes were best modelled by reduction in both $\mathrm{Na}^{+}$and $\mathrm{K}^{+}$channel function. Marked This article is protected by copyright. All rights reserved. 
reduction in motor unit numbers associated with strikingly enlarged motor units have been identified distal to the site of block in patients with $\mathrm{MMN}^{28}$. Furthermore, axonal degeneration has been shown to be strongly associated with block suggesting that the same pathophysiology is likely to account for both processes ${ }^{29}$. Accordingly, a reduction in $\mathrm{Na}^{+}$ and $\mathrm{K}^{+}$channel function may represent a process of a generalised reduction in channel density along enlarged axons with an increased load. A similar pattern of excitability change has been reported in single unit studies undertaken in patients with motor neuron disease, attributed to reduced channel densities along an enlarged axon supplying an abnormally large load of muscle fibres, and impaired axonal transport of membrane proteins and channels resulting from the disease process ${ }^{30}$.

Furthermore, excitability studies in motor axons undergoing degeneration due to proximal nerve transection demonstrated similar changes in TE and superexcitability attributed to a reduction in $\mathrm{Na}^{+}$and $\mathrm{K}^{+}$channel function ${ }^{31}$. Hence, there may be a contribution of degenerating axons (which are still able to conduct), to the axonal abnormalities seen in MMN.

A further consideration to account for the excitability changes in MMN is the possibility of paranodal dysfunction given that GM1 is abundant in the nodo-paranodal region ${ }^{9}$. However, an elevation in motor thresholds was not observed in MMN as would be expected with paranodal dysfunction due to the effect on GBB. Furthermore, paranodal dysfunction was not evident in MMN patients on teased nerve fibre studies.

This article is protected by copyright. All rights reserved. 
Indirect immunofluorescence results from the present study demonstrate that conduction block in CIDP is associated with a high incidence of serum binding to teased nerve fibres, suggesting that yet-to-be identified antibodies are targeting peripheral nerve components. A subset of patients tested negative for binding at the node, paranode or myelin. This group may include those in whom disease is primarily mediated by cellular immunity, rather than antibody response, in addition to patients with low-level antibodies or antibodies that have been cleared following treatment.

The present study has demonstrated the heterogeneity in clinical phenotypes in immunemediated neuropathies. The tools used in the present series can be utilised to further understanding of disease pathophysiology in the inflammatory neuropathies. While imaging techniques can provide information on nerve structure, axonal excitability techniques are an in vivo method of assessing axonal function with mathematical modelling representing a tool to assist in interpretation of excitability results.

\section{REFERENCES}

1. Kaji R, Kimura J. Nerve conduction block. Current Opinion Neurology 1991;4(5):744-748.

2. Mathey EK, Park SB, Hughes RA, et al. Chronic inflammatory demyelinating polyradiculoneuropathy: from pathology to phenotype. Journal Neurology Neurosurgery Psychiatry 2015;86(9):973-985.

3. Garg N, Park SB, Yiannikas C, et al. Neurofascin-155 IgG4 Neuropathy:Pathophysiological insights, spectrum of clinical severity and response to treatment. Muscle Nerve 2018;57:848-851.

4. Querol L, Nogales-Gadea G, Rojas-Garcia R, et al. Antibodies to contactin-1 in chronic inflammatory demyelinating polyneuropathy. Annals Neurology 2013;73(3):370-380.

5. Querol L, Nogales-Gadea G, Rojas-Garcia R, et al. Neurofascin IgG4 antibodies in CIDP associate with disabling tremor and poor response to IVIg. Neurology 2014;82(10):879-886.

This article is protected by copyright. All rights reserved. 
6. Doppler K, Appeltshauser L, Villmann C, et al. Auto-antibodies to contactin-associated protein 1 (Caspr) in two patients with painful inflammatory neuropathy. Brain 2016;139(Pt 10):26172630.

7. Mathey EK, Garg N, Park SB, et al. Autoantibody responses to nodal and paranodal antigens in chronic inflammatory neuropathies. Journal Neuroimmunology 2017;309:41-46.

8. Querol L, Rojas-Garcia R, Diaz-Manera J, et al. Rituximab in treatment-resistant CIDP with antibodies against paranodal proteins. Neurolology Neuroimmunology Neuroinflammation 2015;2(5):e149.

9. Willison HJ, Yuki N. Peripheral neuropathies and anti-glycolipid antibodies. Brain 2002;125(Pt 12):2591-2625.

10. Vlam L, van der Pol WL, Cats EA, et al. Multifocal motor neuropathy: diagnosis, pathogenesis and treatment strategies. Nature Reviews Neurology 2011;8(1):48-58.

11. Van den Bergh PYK, Hadden RDM, Bouche P, et al. EFNS/PNS Guideline on management of chronic inflammatory demyelinating polyradiculoneuropathy: Report of a joint task force of the EFNS/PNS-First Revision. Journal of the Peripheral Nervous System 2010;15(1):1-9.

12. Joint Task Force of the EFNS/PNS guideline on management of multifocal motor neuropathy. Report of a joint task force of the European Federation of Neurological Societies and the Peripheral Nerve Society-first revision. Journal of the Peripheral Nervous System 2010;15(4):295-301.

13. Lin CS, Krishnan AV, Park SB, Kiernan MC. Modulatory effects on axonal function after intravenous immunoglobulin therapy in chronic inflammatory demyelinating polyneuropathy. Archives Neurology 2011;68(7):862-869.

14. Leger JM, Lievens I. Multifocal motor neuropathy: and then, 20 years later...IVIg therapy. Schweizer Archiv für Neurologie und Psychiatrie 2007;158:81-85.

15. Merkies IS, Schmitz PI, Samijn JP, Meche FG, Toyka KV, van Doorn PA. Assessing grip strength in healthy individuals and patients with immune-mediated polyneuropathies. Muscle Nerve 2000;23(9):1393-1401.

16. Merkies IS, Schmitz PI, van der Meche FG, et al. Clinimetric evaluation of a new overall disability scale in immune mediated polyneuropathies. Journal Neurology Neurosurgery Psychiatry 2002;72(5):596-601.

17. Kiernan MC, Burke D, Andersen KV, Bostock H. Multiple measures of axonal excitability: a new approach in clinical testing. Muscle Nerve 2000;23(3):399-409.

18. Kiernan $\mathrm{MC}$, Bostock $\mathrm{H}$. Effects of membrane polarization and ischaemia on the excitability properties of human motor axons.Brain 2000;123:2542-2551.

19. Krishnan AV, Lin CS, Park SB, Kiernan MC. Axonal ion channels from bench to bedside: a translational neuroscience perspective. Progress Neurobiology 2009;89(3):288-313.

This article is protected by copyright. All rights reserved. 
20. Czesnik D, Howells J, Negro F, et al. Increased HCN channel driven inward rectification in benign cramp fasciculation syndrome.Brain 2015;138(Pt 11):3168-3179.

21. Bostock $\mathrm{H}$, Baker $\mathrm{M}$, Reid $\mathrm{G}$. Changes in excitability of human motor axons underlying postischaemic fasciculations: evidence for two stable states. Journal Physiology 1991;441:537-57.

22. Howells J, Trevillion L, Bostock H, Burke D. The voltage dependence of $\mathrm{I}(\mathrm{h})$ in human myelinated axons. Journal Physiology 2012;590(7):1625-1640.

23. Kiernan MC, Isbister GK, Lin CS, Burke D, Bostock H. Acute tetrodotoxin-induced neurotoxicity after ingestion of puffer fish. Annals Neurology 2005;57(3):339-348.

24. Noto Y, Shiga K, Tsuji Y, et al. Nerve ultrasound depicts peripheral nerve enlargement in patients with genetically distinct Charcot-Marie-Tooth disease. Journal Neurology Neurosurgery Psychiatry 2015;86(4):378-384.

25. McIntyre CC, Richardson AG, Grill WM. Modeling the excitability of mammalian nerve fibers: influence of afterpotentials on the recovery cycle. Journal Neurophysiology 2002;87(2):995-1006.

26. Stephanova DI, Daskalova MS, Alexandrov AS. Differences in membrane properties in simulated cases of demyelinating neuropathies: internodal focal demyelinations without conduction block. Journal Biology Physiology 2006;32(2):61-71.

27. Kiernan MC, Guglielmi JM, Kaji R, Murray NM, Bostock H. Evidence for axonal membrane hyperpolarization in multifocal motor neuropathy with conduction block. Brain 2002;125(Pt 3):664675.

28. Garg N, Howells J, Yiannikas C, et al. Motor unit remodelling in multifocal motor neuropathy: The importance of axonal loss. Clinical Neurophysiology 2017;128(10):2022-8028.

29. Vucic S, Black K, Chong PS, Cros D. Multifocal motor neuropathy with conduction block: Distribution of demyelination and axonal degeneration. Clinical Neurophysiology 2007;118(1):124130.

30. Howells J, Matamala JM, Park SB et al. In vivo evidence for reduced ion channel expression in motor axons of patients with amyotrophic lateral sclerosis. Journal Physiology 2018; Sep 2. doi: 10.1113/JP276624.

31. Moldovan M, Alvarez S, Krarup C. Motor axon excitability during Wallerian degeneration. Brain 2009;132:511-523.

This article is protected by copyright. All rights reserved. 
Table 1. Clinical features and median NCS of disease cohorts*

\begin{tabular}{|c|c|c|c|}
\hline & $\begin{array}{l}\text { MMN (CB) } \\
(n=11)\end{array}$ & $\begin{array}{l}\text { CIDP (CB) } \\
(n=11)\end{array}$ & CIDP $(n=33)$ \\
\hline Age (yrs) & $54.82 \pm 11.7$ & $56.4 \pm 15.9$ & $57.8 \pm 15.1$ \\
\hline Sex (M:F) & $6: 5$ & $4: 7$ & $20: 13$ \\
\hline Disease duration (yrs) & $12.4 \pm 7.3$ & $15.9 \pm 13.7$ & $8.7 \pm 8.3$ \\
\hline $\begin{array}{l}\text { CIDP Phenotype } \\
\text { Typical [n(\%)] } \\
\text { DADS [n(\%)] } \\
\text { MADSAM [n(\%)] } \\
\text { Focal [n(\%)] } \\
\text { Motor predominant }[\mathrm{n}(\%)] \\
\text { Sensory predominant }[\mathrm{n}(\%)]\end{array}$ & $\begin{array}{l}- \\
- \\
- \\
- \\
- \\
-\end{array}$ & $\begin{array}{l}7(64 \%) \\
0(0 \%) \\
1(9 \%) \\
0(0 \%) \\
2(18 \%) \\
1(9 \%) \\
\end{array}$ & $\begin{array}{l}16(48 \%) \\
3(9 \%) \\
7(28 \%) \\
2(6 \%) \\
1(3 \%) \\
4(12 \%) \\
\end{array}$ \\
\hline $\begin{array}{l}\text { Treatment } \\
\text { IVIg (\%) } \\
\text { Additional immunosuppression } \\
\end{array}$ & $\begin{array}{l}11(100 \%) \\
1(9 \%)\end{array}$ & $\begin{array}{l}9(82 \%) \\
3(27 \%)\end{array}$ & $\begin{array}{l}32(97 \%) \\
10(30 \%)\end{array}$ \\
\hline $\begin{array}{l}\text { Clinical scores } \\
\text { MRC sum-score }(/ 70) \\
\text { E-MRC sum-score }(/ 150) \\
\text { Grip strength (kg force) } \\
\text { INCAT ODSS (/12) }\end{array}$ & $\begin{array}{l}\text { N/A } \\
134.7 \pm 8.4 \\
19.4 \pm 11.5 \\
\text { N/A }\end{array}$ & $\begin{array}{l}64.8 \pm 5.1 \\
\text { N/A } \\
19.6 \pm 11.4 \\
2.8 \pm 1.0\end{array}$ & $\begin{array}{l}66.2 \pm 4.4 \\
\text { N/A } \\
23.1 \pm 10.8 \\
2.9 \pm 1.4\end{array}$ \\
\hline $\begin{array}{l}\text { Median NCS results } \\
\text { DML }(\mathrm{ms}) \\
\text { CMAP }(\text { wrist })(\mathrm{mV}) \\
\text { CMAP }(\text { elbow })(\mathrm{mV}) \\
\text { Forearm CV }(\mathrm{m} / \mathrm{s}) \\
\text { Wrist to elbow area reduction }(\%)\end{array}$ & $\begin{array}{l}3.3 \pm 1.0 \\
7.2 \pm 2.8 \\
2.3 \pm 1.4 \\
42.5 \pm 13.0 \\
56.7 \pm 21.1\end{array}$ & $\begin{array}{l}4.5 \pm 1.7 \\
5.6 \pm 3.7 \\
2.2 \pm 1.6 \\
31.8 \pm 7.5 \\
58.8 \pm 22.3\end{array}$ & $\begin{array}{l}4.6 \pm 1.9 \\
6.9 \pm 3.1 \\
6.2 \pm 2.2 \\
44.3 \pm 9.1 \\
4.7 \pm 12.2\end{array}$ \\
\hline
\end{tabular}

$*$ mean \pm SD

\# patients administered prednisone, mycophenolate, azathioprine in addition to IVIg

MRC sum-score:Medical Research Council sum-score;E-MRC:expanded Medical Research Council sum-score; INCAT ODSS:INCAT overall disability sum score;DML:distal motor latency;CMAP:compound muscle action potential;CV:conduction velocity

This article is protected by copyright. All rights reserved. 
Table 2. Excitability measurements*

\begin{tabular}{|c|c|c|c|c|c|c|}
\hline Excitability measure & $\begin{array}{l}\text { Healthy } \\
\text { Controls } \\
(\mathbf{n}=29)\end{array}$ & $\begin{array}{r}\text { MMN } \\
(\mathbf{C B}) \\
(\mathbf{n}=9)\end{array}$ & $\begin{array}{r}\text { CIDP } \\
(\text { CB }) \\
(\mathbf{n}=7)\end{array}$ & $\begin{array}{l}\text { CIDP } \\
(n=26)\end{array}$ & $\begin{array}{c}\text { P-value } \\
\text { MMN(CB) } \\
\text { vs } \\
\text { CIDP(CB) } \\
\end{array}$ & $\begin{array}{c}\text { P-value } \\
\text { CIDP(CB) } \\
\text { vs CIDP }\end{array}$ \\
\hline Peak (mV) & $8.6 \pm 0.6$ & $7.5 \pm 0.5$ & $6.9 \pm 1.3$ & $7.9 \pm 0.6$ & ns & ns \\
\hline $\begin{array}{l}\text { Threshold properties } \\
\text { Stim for } 50 \% \text { response }(\mathrm{mA}) \\
\text { SR slope } \\
\text { Rheobase }(\mathrm{mA})\end{array}$ & $\begin{array}{l}3.7 \pm 0.3 \\
4.8 \pm 0.3 \\
2.5 \pm 0.2\end{array}$ & $\begin{array}{l}5.1 \pm 0.7^{\mathrm{ns}} \\
4.3 \pm 1.1^{\mathrm{ns}} \\
3.2 \pm 0.3^{\mathrm{ns}}\end{array}$ & $\begin{array}{l}13.0 \pm 2.1^{* * * *} \\
3.0 \pm 0.7^{\mathrm{ns}} \\
9.0 \pm 1.7^{* * *}\end{array}$ & $\begin{array}{l}6.4 \pm 0.8^{* *} \\
4.6 \pm 0.6^{\mathrm{ns}} \\
4.1 \pm 0.6^{\mathrm{ns}}\end{array}$ & $\begin{array}{l}\text { ns } \\
\text { ns } \\
\text { ns }\end{array}$ & $\begin{array}{l}\mathrm{ns} \\
\mathrm{ns} \\
\mathrm{ns}\end{array}$ \\
\hline $\begin{array}{l}\text { Internodal function } \\
\text { TEh }(90-100)(\%) \\
\text { TEd }(90-100)(\%) \\
\text { TEd20 }(10-20)(\%) \\
\text { TEh20 }(10-20)(\%)\end{array}$ & $\begin{array}{l}-113.3 \pm 3.3 \\
44.7 \pm 0.7 \\
34.4 \pm 0.5 \\
-37.2 \pm 0.9\end{array}$ & $\begin{array}{l}-147.6 \pm 8.1 * * * * \\
53.1 \pm 1.8^{* * * *} \\
39.6 \pm 1.3^{* *} \\
-39.3 \pm 1.3^{\mathrm{ns}}\end{array}$ & $\begin{array}{l}-194.0 \pm 13.4 * * * * \\
52.4 \pm 1.5 * * * \\
44.7 \pm 2.1 * * * \\
-50.1 \pm 3.2 * * *\end{array}$ & $\begin{array}{l}-119 \pm 2.4^{\mathrm{ns}} \\
46.8 \pm 0.8^{\mathrm{ns}} \\
35.0 \pm 0.6^{\mathrm{ns}} \\
-36.9 \pm 0.8^{\mathrm{ns}}\end{array}$ & $\begin{array}{c}<0.0001 \\
\mathrm{~ns} \\
\mathrm{~ns} \\
\mathrm{~ns}\end{array}$ & $\begin{array}{l}<0.0001 \\
<0.05 \\
<0.001 \\
<0.001\end{array}$ \\
\hline
\end{tabular}

*mean(SEM)

$* * * *<0.0001 ; * * *<0.001 ; * *<0.01 ; \mathrm{ns}=$ not significant compared with HC

This article is protected by copyright. All rights reserved. 


\section{FIGURE LEGENDS}

\section{Figure 1. Excitability profiles in CIDP and MMN patients}

Figure Legend: (A and B) marked changes in threshold electrotonus (TE) and recovery cycle $(\mathrm{RC})$ in patients with $\mathrm{MMN}(\mathrm{CB}) ;(\mathrm{C}$ and $\mathrm{D})$ marked changes in TE without superexcitability change in patients with CIDP (CB);(E and F) CIDP (CB) and MMN (CB) have differing TE and RC profiles; ( $\mathrm{G}$ and $\mathrm{H}$ ) CIDP patients without median motor block did not differ from healthy controls in TE and RC parameters.

$M M N($ red ); $C I D P(C B)($ blue $) ; C I D P($ green $) ;$ Healthy controls(grey)

\section{Figure 2. Motor nerve excitability scatter plots}

Figure Legend: Stimulus response curve, demonstrating increase in threshold in CIDP (CB) group with curve shifted to the right (A). Greater threshold changes in threshold electrotonus (TE) both in hyperpolarising and depolarising directions (B and C, respectively). Marked increase in superexcitability in MMN patients not seen in CIDP patients (D).

$M M N($ red $) ; C I D P(C B)($ blue ); CIDP(green); Healthy controls(grey)

Figure 3: Patterns of serum binding observed using indirect immunofluorescence with healthy control and CIDP serum on teased nerve fibres.

Teased fibres were triple stained for human IgG (green, left column), neurofascin (red) and caspr (blue) using serum from healthy controls (A,B) or CIDP patients $(\mathrm{C}-\mathrm{H})$. Serum from healthy controls did not bind to the teased nerve fibres while serum from some CIDP patients This article is protected by copyright. All rights reserved. 
bound to the node of Ranvier (C,D), the paranode (E, F) or to myelin/Schwann cell $(\mathrm{G}, \mathrm{H})$. Bar=10um
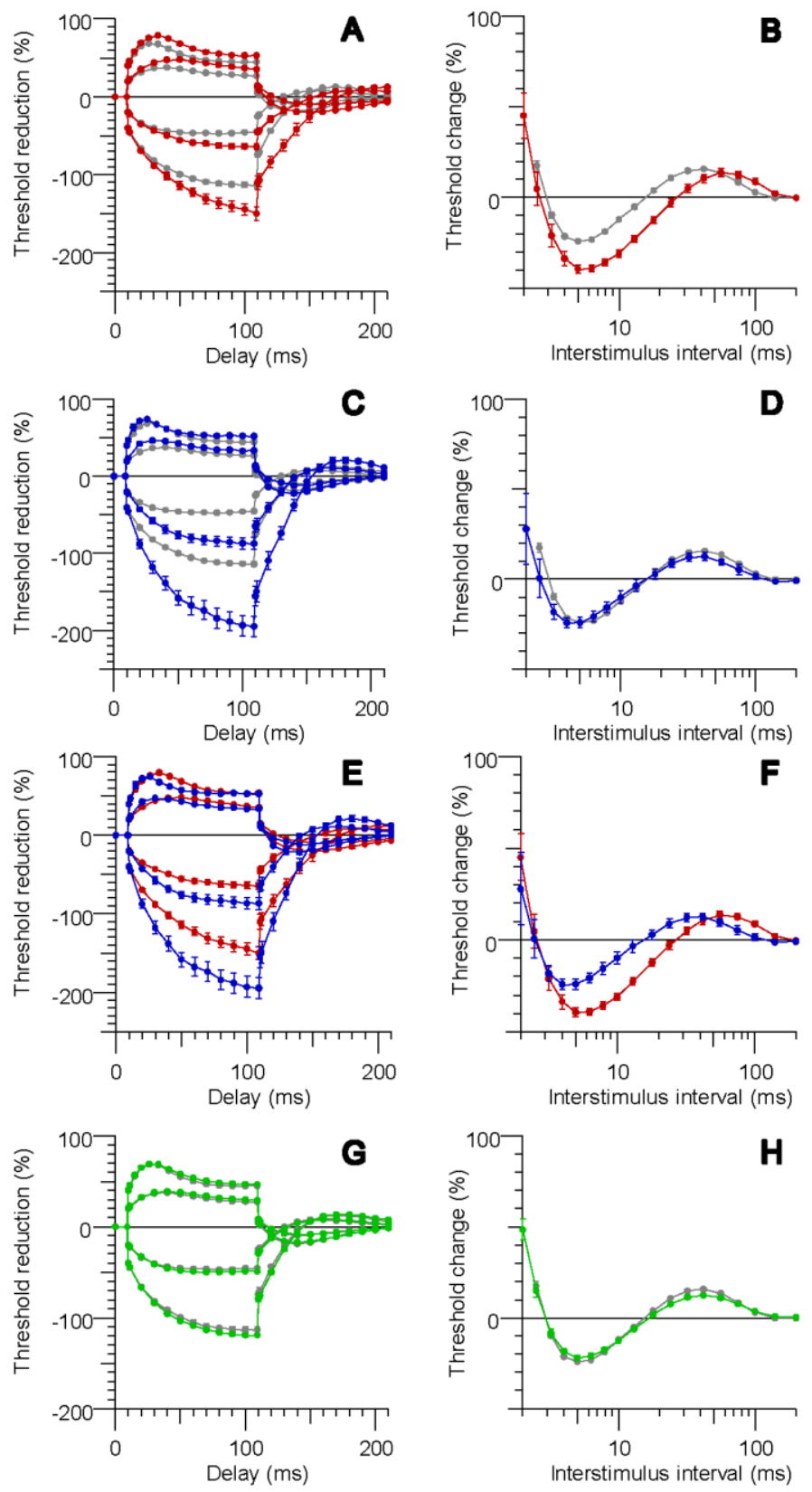

This article is protected by copyright. All rights reserved. 

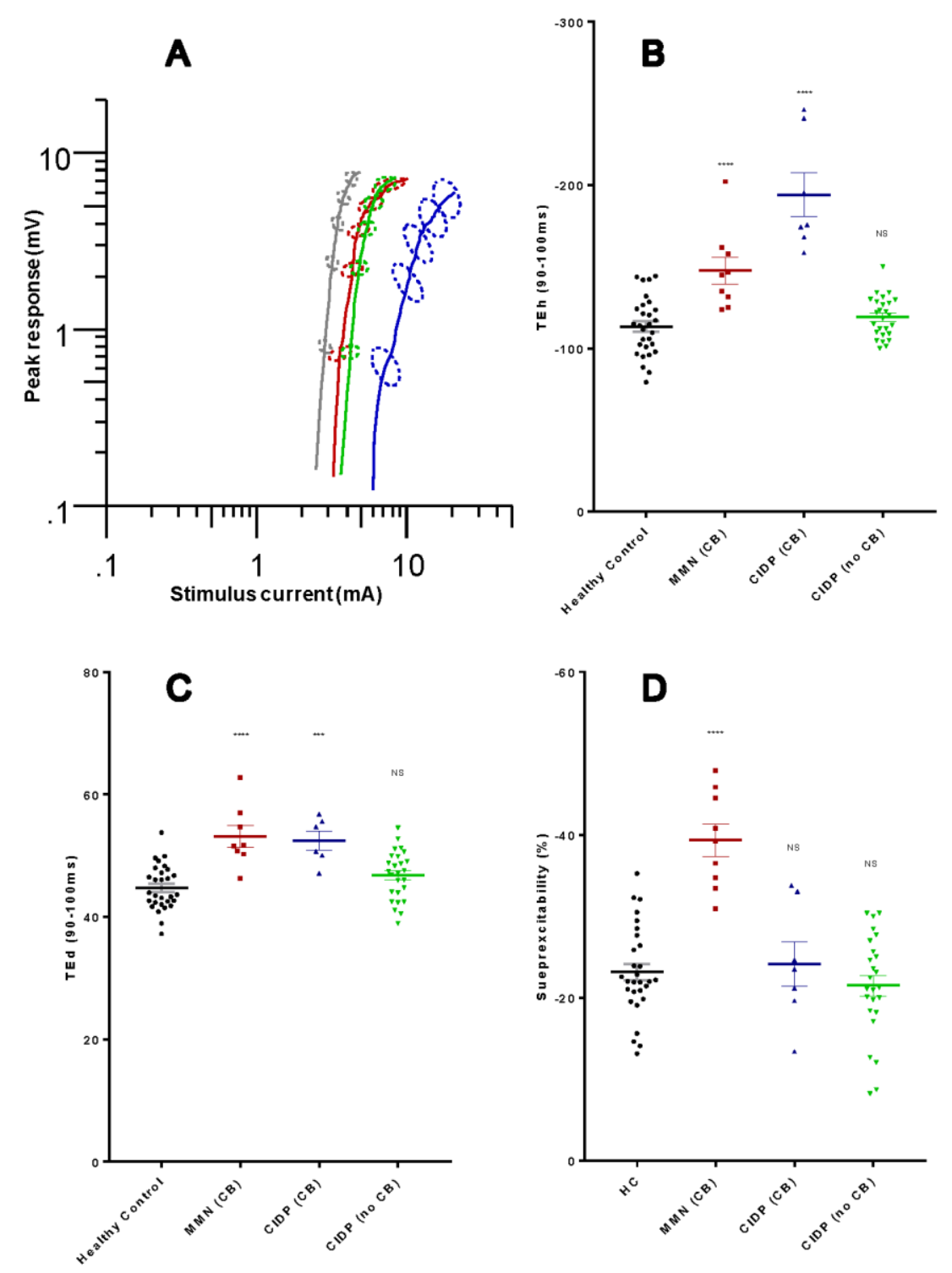

This article is protected by copyright. All rights reserved. 

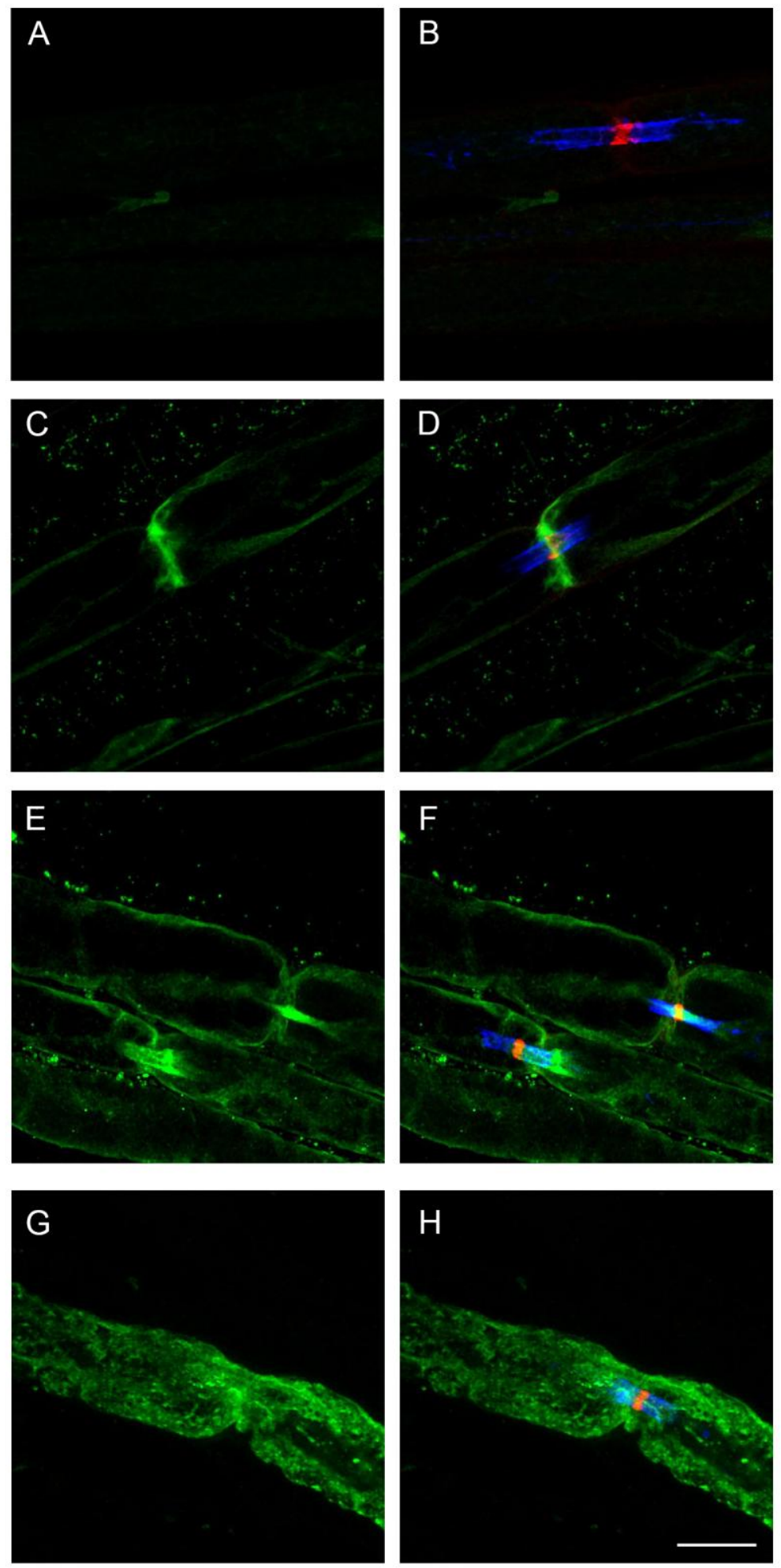

This article is protected by copyright. All rights reserved. 